\title{
Spatial Orientation In Sportsmen
}

\author{
Stanislava Stoyanova, Prof., PhD \\ Nikolay Ivantchev, PhD
}

Department of Psychology,

South-West University “Neofit Rilski”, Blagoevgrad, Bulgaria

Kremka Petrova, Assoc. Prof., PhD

Department of Sport,

South-West University “Neofit Rilski”, Blagoevgrad, Bulgaria

\section{doi: 10.19044/esj.2016.v12n24p88 URL:http://dx.doi.org/10.19044/esj.2016.v12n24p88}

\begin{abstract}
Cognitive processes are important for successful practicing of sport. 69 national and regional competitors in different kinds of sports were studied by means of 2D Visualisation, the subtest "Comparing surfaces" of AHA and GESTA - computerized test methods from Vienna Test System measuring spatial orientation, precision of estimation of the size of the surfaces, and perception of more or few details in visual environment respectively. There were not any significant gender differences in athletes' spatial orientation. Longer period of sports training was related to better spatial orientation.
\end{abstract}

Keywords: Athletes, gender, spatial orientation, sports practice

\section{Introduction}

The sports activity requires implementation of the whole personal potential - physical and mental, for achievement of high sports results. Mental readiness and manifested motor skills are the parts of the success formula in every sport. Athletes' mental preparedness assists their performance.

Cognitive processes are important for optimal athletic performance. Individuals practicing different kinds of sports may differ in their cognitive abilities related to the characteristics of the activity, different training skills and expertise (Sanchez-Lopez et al., 2014).

It is important the athletes and the coaches to know well the athlete's possibilities and their mental peculiarities. For example, a study among athletes practicing tennis revealed that cognitive expertise developed by means of video-feedback and questioning produced some improvement in tactical knowledge and successful decisions made during game play (García- 
González, 2013). The skilled tennis players based more successfully their inferences to situational probabilities and pattern recognition than their novice counterparts (Williams, Ford, Eccles \& Ward, 2011).

Other research findings indicate that relaxation training embodies cognitive processes with sensory-motor processes and it has a positive effect on taekwondo athletes' performance (Ottoboni, Giusti, Gatta, Symes \& Tessari, 2014). On the other hand, practicing combat sports strengthens mental resistance (Yordanov, 2013). This illustrates the relationship between mental processes and performance.

The studies of athletes' cognitive functions typically emphasize on a few cognitive processes in one kind of sport. This study is focused on spatial orientation in different types of sports - team sports (such as football, handball, volleyball, badminton and curling) and individual sports (like biathlon, tennis, track and field athletics, aerobics and fitness, swimming, snowboard, and combat sports - taekwondo, judo, sambo, and Muai Thai). Interactive sports (such as football, basketball, handball, etc.) are practiced always in teams and they entail co-ordination of actions between team members. Co-active sports (such as biathlon, tennis, etc.) involve typically individual activity, but they are practiced sometimes in a team framework (Lavallee, Kremer, Moran \& Williams, 2004). Biathlon could be played in relay and tennis could be played in couples. Performance in all sports requires good spatial orientation. For example, combat sports are supposed to require good spatial orientation, because the quality, speed and stability of spatial orientation are related to coordination abilities (Klaček, Slančová \& Junger, 2006) that are required in combat sports. The small numbers of athletes practicing different sports were unified in one studied group. The aim of this study was to be specified athletes' spatial orientation in relation to their gender, training period and experience as elite and regional competitors.

\section{Spatial orientation}

Spatial orientation as a cognitive function is a part from perceptual and visuospatial clusters of cognitive subtypes (Cappa, Ciccarelli, Baldonero, Martelli \& Silveri, 2014), cluster 'visuospatial' of cognitive variability (Lewandowski, Sperry, Cohen \& Öngür, 2014), cluster Visual processing from Stratum II of the Cattell-Horn-Carroll theory of cognitive abilities (McGrew, 2009). That is why its study requires execution of some visual tasks.

Spatial orientation is related to visual perception. It has been found that field-independent people orientate themselves by the position of their own body, and field-dependent persons refer themselves to the position of the visual frame (Schuster, 2003). 
Spatial ability consists of spatial perception, spatial visualization (mental rotation and manipulation of objects in two or three dimensions), and spatial orientation - awareness of one's current location and location of simple figures within complex figures (Bergqvist, 2015; Lord \& Garrison, 1998). These components are related between them and spatial perception and spatial visualisation are immanent parts of spatial orientation as one can summarize from the viewpoints below.

Spatial orientation is an aspect of intellectual capacity as the ability to perceive and mentally manipulate figures in various dimensions from a new perspective, fast and correctly; to organize thoughts on the basis of mental pictures - visualisation (Bratfisch, Hagman \& Bognar, 2004b); to comprehend imaginary movement in two- or three-dimensional space; to remain unconfused in changed orientation of a spatial configuration (Risma, 2013); to form and use cognitive maps - complex mental representations of the environment based on environmental landmarks and spatial relationships (Bergqvist, 2015).

There are some controversial findings regarding gender differences in spatial orientation.

In some sports common to both sexes as basketball, female college athletes had higher scores than males on spatial tests, but in some other sports practiced by both sexes as swimming and track and field athletics, there were not any significant gender differences in spatial abilities (Lord \& Garrison, 1998). Men perform better than women concerning their spatial abilities, for example in mental rotation (Bergqvist, 2015, p.7). A study conducted among 4-5 year-old children, revealed that there were nonsignificant differences between boys and girls, between the children who did or did not participate in sports in their spatial orientation ability (Pollatou, Gerodimos, Zissi, Zervano \& Karadimou, 2009). These controversial findings regarding gender differences in spatial orientation could be explained by the differences in the type of the practiced sport, the type of the required task for measuring spatial orientation, the age and the period of sports training and experience. The hypothesis of this study stated the nonexistence of gender difference in spatial orientation in athletes and improvement of their spatial orientation with a longer period of sports experience and training. Better performance of one gender group in one type of sport could be compensated by better performance of the opposite sex in another type of sport, and as a whole, no gender differences in athletes' spatial orientation were expected.

Spatial orientation could be measured by means of tasks related to breaking an entity into its parts or composing an entity from some parts (flexibility of closure), quick identification of an incomplete picture (closure speed), recognition of relations between objects when the starting point is the 
one's own body orientation - for example discrimination between left-right (kinaesthetic), finding visually the correct path in a labyrinth (spatial scanning), recognition of a previously presented figure (visual memory), integration of spaced visual stimuli (serial integration), perceptual speed (Bratfisch, Hagman \& Bognar, 2004b), map-reading (Risma, 2013), finding target space/location (Bergqvist, 2015), etc.

The methods used for this study included several practical tasks to be performed by the athletes that required identification of an incomplete picture, recognition of the relations between the objects, composing an entity from some parts, perceptual speed, estimation of the size of a couple of similar surfaces, and perception of more or few details in visual spatial stimuli in complex environment.

\section{Method}

Several psychological studies were conducted from 2012 to 2015 among sportsmen from the sports clubs at South-West University "Neofit Rilski" in Blagoevgrad, Bulgaria and National Sports Academy "Vassil Levski” in Sofia, Bulgaria.

All subjects participated voluntarily and agreed to be studied. The results are presented anonymously.

\section{Participants}

The participants in the study were 69 athletes in total. 26 were females and 43 were males. 12 were the national athletes (practicing biathlon and taekwondo). 57 were the regional athletes practicing various sports.

For group comparisons, each group should consist of at least 12 members (Johanson \& Brooks, 2010), so the national and regional competitors' results could be compared in this study.

The regional competitors practiced: combat sports (12 were the regional competitors in judo, sambo, Muai Thai, and taekwondo - 9 males and 3 females); football (10 men); aerobics and fitness ( 8 females); handball (7 males); track and field athletics ( 7 females); tennis (3 men and 4 women); volleyball (2 men); swimming (2 females); badminton and curling (1 male); snowboard (1 male).

The national competitors practiced: taekwondo (7 men) and biathlon (4 men and 1 woman),

Their mean time of sports practice was 10 years ( $\mathrm{SD}=3.8$ years). They have practiced sport from 3 years to 20 years. There were not any significant differences (Mann-Whitney $U=247.5$; $p=.133$ ) between the period of sports training and experience of the studied national $(\mathrm{M}=9.8$; $\mathrm{SD}=5$; Mean Rank $=42.88)$ and regional competitors $(\mathrm{M}=8.6 ; \mathrm{SD}=10$; Mean Rank = 33.34). 
The athlete's mean age was 25.3 years old $(\mathrm{SD}=9.6)$. There were not any significant differences (Mann-Whitney $\mathrm{U}=333$; $\mathrm{p}=.885$ ) between the age of the studied national $(\mathrm{M}=23.6 ; \mathrm{SD}=4.6$; Mean Rank = 35.75) and regional competitors $(\mathrm{M}=25.7$; $\mathrm{SD}=10.3$; Mean Rank = 34.84).

\section{Instruments}

The computerized test method “2D Visualisation” from Vienna test system was used for measuring spatial orientation. This computerized method had a training phase and a testing phase. A given figure had to be completed. One, two or three parts of it were missing and the respondent should select them from 16 segments given below for a time limit. High number of correctly solved items means better spatial orientation (Bratfisch, Hagman \& Bognar, 2004a). In the studied sample, its Cronbach's alpha was .783 .

The subtest "Comparing surfaces" of the computerized test method AHA from Vienna test system was used for assessment of precision of estimation of the size of the surfaces. The respondent answered which one of two figures had a bigger surface (Kubinger, Ebenhöh, Karner \& Sommer, 2003). In the studied sample, its Cronbach's alpha was .716.

The computerized test method GESTA from Vienna test system was used for assessment of the cognitive style of field (in)dependence by identifying a specific shape (a familiar object - a house) integrated into a complex environment of many other visual stimuli. The participant had 20 seconds per item to find the solution (Schuster, 2003). A subject with a high number of correctly solved items is field-independent using more details in visual perception for spatial orientation. Field-dependent persons perceive situations in a complex way using few details in visual perception for spatial orientation. In the studied sample, Cronbach's alpha of GESTA was .732.

\section{Data processing}

Data were statistically processed by means of SPSS 16 . Nonparametric statistical methods were applied because of the small and unequal number of the participants in the compared groups of the national and regional sportsmen, as well as the male and female athletes. Pearson correlation coefficients between the scores on spatial orientation, precise estimation of surfaces, field (in)dependence, age, and the period of sports training and experience were computed. Linear regression analysis was performed with the period of sports training as an independent variable and the scores on spatial orientation as the dependent variable. 


\section{Results}

The results were compared between the national and the regional competitors, and between gender groups.

Table 1 Results of the national and regional competitors concerning spatial orientation

\begin{tabular}{|c|c|c|c|c|c|}
\hline Variable & $\begin{array}{c}\text { Kinds of } \\
\text { competitors }\end{array}$ & Mean rank & $\begin{array}{c}\text { Mann- } \\
\text { Whitney } U\end{array}$ & $p$ & Effect size \\
\hline \multirow{2}{*}{$\begin{array}{l}2 D \text { - spatial } \\
\text { orientation }\end{array}$} & $\begin{array}{c}\text { National } \\
\text { competitors }\end{array}$ & 49.88 & \multirow{2}{*}{163.5} & \multirow{2}{*}{.004} & \multirow{2}{*}{$r=-0.343$} \\
\hline & $\begin{array}{c}\text { Regional } \\
\text { competitors }\end{array}$ & 31.87 & & & \\
\hline \multirow{2}{*}{$\begin{array}{c}\text { AHA - precision of } \\
\text { estimation of } \\
\text { surfaces }\end{array}$} & $\begin{array}{c}\text { National } \\
\text { competitors }\end{array}$ & 26.12 & \multirow{2}{*}{235.5} & \multirow{2}{*}{.331} & \multirow{2}{*}{$r=-0.126$} \\
\hline & $\begin{array}{c}\text { Regional } \\
\text { competitors }\end{array}$ & 31.59 & & & \\
\hline \multirow{2}{*}{\begin{tabular}{|c|} 
GESTA - using \\
more or few details \\
in visual \\
perception
\end{tabular}} & $\begin{array}{c}\text { National } \\
\text { competitors }\end{array}$ & 35.25 & \multirow{2}{*}{147} & \multirow{2}{*}{.035} & \multirow{2}{*}{$r=-0.29$} \\
\hline & $\begin{array}{c}\text { Regional } \\
\text { competitors }\end{array}$ & 24.59 & & & \\
\hline
\end{tabular}

The national competitors had better spatial orientation and they used more details in visual perception (they were more field independent) than the regional competitors (see Table 1 ). The national and regional competitors did not differ significantly in the precision of their estimation of the size of the surfaces (see Table 1 ).

Table 2 Results regarding gender comparison concerning spatial orientation

\begin{tabular}{|c|c|c|c|c|c|}
\hline Variable & Gender & Mean rank & $\begin{array}{c}\text { Mann- } \\
\text { Whitney } U\end{array}$ & $p$ & Effect size \\
\hline \multirow{2}{*}{$2 D$ - spatial orientation } & Males & 37.55 & \multirow{2}{*}{449.5} & \multirow{2}{*}{.172} & \multirow{2}{*}{$r=-0.165$} \\
\hline & Females & 30.79 & & & \\
\hline \multirow{2}{*}{$\begin{array}{l}\text { AHA - precision of } \\
\text { estimation of surfaces }\end{array}$} & Males & 31.82 & \multirow{2}{*}{368} & \multirow{2}{*}{.442} & \multirow{2}{*}{$r=-0.099$} \\
\hline & Females & 28.23 & & & \\
\hline \multirow{2}{*}{$\begin{array}{l}\text { GESTA - using more or } \\
\text { few details in visual } \\
\text { perception }\end{array}$} & Males & 26.8 & \multirow{2}{*}{323.5} & \multirow{2}{*}{.905} & \multirow{2}{*}{$r=-0.016$} \\
\hline & Females & 27.32 & & & \\
\hline
\end{tabular}

There were not any significant gender differences in the athletes' spatial orientation, neither in their estimation of the size of the surfaces, neither in their field independence (see Table 2). 
Table 3 Pearson correlation coefficients between the athletes' scores on spatial orientation, their age and the period of their sports experience and training

\begin{tabular}{|c|c|c|c|c|c|c|}
\hline \multicolumn{2}{|l|}{ variables } & $\begin{array}{c}\text { Spatial } \\
\text { orientation } \\
2 D\end{array}$ & Age & $\begin{array}{l}\text { Period of } \\
\text { sports } \\
\text { experience }\end{array}$ & $\begin{array}{l}\text { Precision of } \\
\text { estimation } \\
\text { of surfaces } \\
\text { - AHA }\end{array}$ & $\begin{array}{c}\text { Field } \\
\text { (in)dependence } \\
\text { - GESTA }\end{array}$ \\
\hline \multirow{2}{*}{$\begin{array}{c}\text { Spatial } \\
\text { orientation } 2 D\end{array}$} & $r$ & 1 & $.254 *$ & $.259 * *$ & -.13 & $.401^{* *}$ \\
\hline & $p$ & & .035 & .031 & .323 & .003 \\
\hline \multirow{2}{*}{ Age } & $r$ & $.254 *$ & 1 & $.846^{* * *}$ & .133 & -.121 \\
\hline & $p$ & .035 & & $<.001$ & .31 & .387 \\
\hline \multirow{2}{*}{$\begin{array}{l}\text { Period of sports } \\
\text { experience }\end{array}$} & $r$ & $.259 * *$ & $.846^{* *}$ & 1 & .173 &.-188 \\
\hline & $p$ & .031 & $<.001$ & & .187 & .178 \\
\hline \multirow{2}{*}{$\begin{array}{c}\text { Precision of } \\
\text { estimation of } \\
\text { surfaces - AHA }\end{array}$} & $r$ & -.13 & .133 & .173 & 1 & -.087 \\
\hline & $p$ & .323 & .31 & .187 & & .534 \\
\hline \multirow{2}{*}{$\begin{array}{c}\text { Field } \\
\text { (in)dependence } \\
\text { - GESTA } \\
\end{array}$} & $r$ & $.401 * *$ & -.121 & -188 & -.087 & 1 \\
\hline & $p$ & .003 & .387 & .178 & .534 & \\
\hline
\end{tabular}

${ }^{*} \mathrm{p}<.05,95 \%$ C.I. $(0.018,0.463) ;{ }^{* *} \mathrm{p}<.05$, 95\% C.I. $(0.024,0.467) ; * * * \mathrm{p}<.00195 \%$ C.I.

$(0.762,0.902)$

Longer period of sports experience was related to better spatial orientation - there was a weak, but significant positive correlation between them. Advance in age was also related significantly, but weak, to the studied athletes' spatial orientation. Better spatial orientation was related to field independence, and the use of more details in visual perception of spatial stimuli, but it was not related to the exact estimation of the size of surface areas (see Table 3).

Linear regression indicated that longer period of sports experience and training predicted better spatial orientation $\left(R=.259 ; R^{2}=.067 ; F_{\mid 1}\right.$, 67|=4.836; $p=.031 ; b=.798 ; t=2.199 ; p=.031$ ).

Longer period of sports experience and training did not predict exact estimation of the size of the surfaces $\left(R=.173 ; R^{2}=.03 ; F_{|1,67|=1.782 ;} p=.187\right.$; $b=.007 ; t=1.335 ; p=.187$ ), neither field (in)dependence - the use of more or few details in visual perception of spatial stimuli $\left(R=.188 ; R^{2}=.035 ; F_{\mid 1}\right.$, 67| $=1.868 ; p=.178 ; b=-.008 ; t=-1.367 ; p=.178)$.

\section{Discussion}

The research findings supported the hypothesis stating the nonexistence of gender difference in spatial orientation in athletes and improvement of their spatial orientation with a longer period of sports experience and training.

The differences in spatial orientation could be due partly to the different level of preparedness and performance among the national and 
regional competitors. It was found that long-term sports practice was related to better spatial orientation as in the case of the national competitors who had average longer (but not significantly more) sports experience ( $\mathrm{M}=9.8$ years; $\mathrm{SD}=5$ years) than the regional competitors did ( $\mathrm{M}=8.6$ years; $\mathrm{SD}=10$ years). National (elite) competitors outreached the regional competitors in their spatial orientation. Longer sports practice improved spatial orientation, independently on the estimation of the size of the surfaces or on perception of more or few details in the environment.

Some other findings also suggest the interdependence between practice and cognitive functioning. Motor expertise enhances flexibility and better cognitive control to the requested task (Sanchez-Lopez et al., 2014).

Computer-based cognitive training is a means to enhance cognitive functions (Voss et al., 2010). Computerized testing could have the effect of computer-based cognitive training because of its training phase preceding the testing phase.

Increase of sports practice with the advance in age, and being a national (elite) or regional competitor determined spatial orientation. The non-existence of gender difference in spatial orientation in athletes could be explained by the fact that they all developed their spatial orientation ability by means of sports training.

The number of male and female athletes practicing different kinds of sports was not big enough in order to be made inter-sport gender comparisons. This limitation could be overcome in further studies.

A sample bigger in number would permit comparisons between the athletes practicing different types of sports. Some research findings indicate that athletes in tennis as an interceptive-dominant sport have faster response times than athletes in self-paced sports such as swimming (Voss, Kramer, Basak, Prakash \& Roberts, 2010) that suppose differences in the speed of visual perception as a component of spatial orientation between the different kinds of sports.

The small size of the compared surfaces could explain the established lack of connection between spatial orientation and the exact estimation of the size of surface areas, and further comparisons of bigger surfaces are necessary for specifying the estimation of surface areas as an aspect of spatial orientation ability.

Psychological studies play an important role for assessment of mental states and processes, and giving directions for their development. If coaches and athletes accept the psychological studies as necessary, cooperate for their conduct and rely on their results, these studies could be useful if the athlete's preparation. The selection and application of psychological methods for the study of athletes clarifies the current status of athlete's psychological potential at the given stage of preparedness. 


\section{Acknowledgments}

This study was partially funded by Bulgarian Ministry of Education and Science as a grant on Decree 9 for the project "Models of psychofunctional studies in sport” SRP-B12/12.

\section{References:}

Bergqvist, E. (2015). Spatial orientation \& imagery. What are the gender differences in spatial orientation and mental imaging when navigating a virtual environment with only auditory cues? A Master degree thesis. Skövde, Sweden: University of Skövde. Retrieved in January 2016, from https://www.diva-portal.org/smash/get/diva2:838614/FULLTEXT01.pdf Bratfisch, O., Hagman, E., \& Bognar, B. (2004a). 2D Visualization. Release 22.00. Mödling, Austria: Dr.G.Schuhfried Ges.m.b.H.

Bratfisch, O., Hagman, E. \& Bognar, B. (2004b). 3D Spatial Orientation. Release 22.00. Mödling, Austria: SCHUHFRIED GmbH.

Cappa, A., Ciccarelli, N., Baldonero, E., Martelli, M., \& Silveri, M. C. (2014). Posterior AD-Type pathology: Cognitive subtypes emerging from a cluster analysis. Behavioural Neurology, 2014, Article ID 259358. doi:10.1155/2014/259358

García-González, L., Moreno, M. P., Moreno, A., Gil, A., \& Del Villar, F. (2013). Effectiveness of a video-feedback and questioning programme to develop cognitive expertise in sport. PLoS ONE, 8(12). doi:10.1371/journal.pone.0082270

Johanson, G. A., \& Brooks, G. P. (2010). Initial Scale Development: Sample Size for Pilot Studies. Educational and Psychological Measurement, 70(3), 394-400. doi:10.1177/0013164409355692

Klaček, T., Slančová, T., \& Junger, J. (2006). The standardization of motor tests of the spatial-orientation coordination abilities of 10, 14, 17 and 20 years old boys/men. Journal of Health Promotion and Recreation, 9(3), 357361.

Kubinger, K. D., Ebenhöh, J., Karner, T., \& Sommer, M. (2003). Attitudes to Work. Short Test Battery: Aspiration level, Frustration tolerance, Performance motivation, Impulsiveness/Reflexivity. Release 26.00. Mödling, Austria: Dr.G.Schuhfried Ges.m.b.H., Verlag Swets Test Services.

Lavallee, D., Kremer, J., Moran, A. P., \& Williams, M. (2004). Sport Psychology: Contemporary themes. New York: Palgrave Macmillan.

Lewandowski, K.E., Sperry, S.H., Cohen, B.M., \& Öngür, D. (2014). Cognitive variability in psychotic disorders: an exploratory cross-diagnostic cluster analysis. Psychological Medicine, 44(15), 3239-48. doi: 10.1017/S0033291714000774 
Lord, T. R., \& Garrison, J. (1998). Comparing spatial abilities of collegiate athletes in different sports. Perceptual and motor skills, 86(3 Pt 1), 10161018.

McGrew, K. (2009). Editorial: CHC theory and the human cognitive abilities project: Standing on the shoulders of the giants of psychometric intelligence research. Intelligence, 37(1), 1-10.

Ottoboni, G., Giusti, R., Gatta, A., Symes, E., \& Tessari, A. (2014). Just do it: Embodied experiences improve Taekwondo athletes sport performance. Sensoria: A Journal of Mind, Brain \& Culture, 10(1), 28-33.

Pollatou, E., Gerodimos, V., Zissi, V., Zervano, D., \& Karadimou, K. (2009). Spatial orientation ability in boys and girls toddlers. Scientific Journal of Orienteering, 17(1), 39-45.

Risma, D. A. (2013). Spatial visualization and spatial orientation tasks to support the development of students' spatial ability. A Master degree thesis. Palembang, South Sumatra, Indonesia: Sriwijaya University, Faculty of Teacher Training and Education. Retrieved in January 2016, from http://www.fisme.science.uu.nl/en/impome/theses_group_2012/thesis_Rini.p df

Sanchez-Lopez, J., Fernandez, T., Silva-Pereyra, J., Martinez Mesa, J. A., \& Di Russo, F. (2014). Differences in visuo-motor control in skilled vs. novice martial arts athletes during sustained and transient attention tasks: A motorrelated cortical potential study. PLoS ONE, 9(3), 1-10. doi:10.1371/journal.pone.0091112

Schuster, B. (2003). Gestalt Perception Test. Release 22.00. Mödling, Austria: Dr.G.Schuhfried Ges.m.b.H.

Voss, M. W., Kramer, A. F., Basak, C., Prakash, R. S., \& Roberts, B. (2010). Are Expert Athletes 'Expert' in the Cognitive Laboratory? A Meta-Analytic Review of Cognition and Sport Expertise. Applied Cognitive Psychology, 24(6), 812-826.

Williams, A. M., Ford, P. R., Eccles, D. W., \& Ward, P. (2011). Perceptualcognitive expertise in sport and its acquisition: Implications for applied cognitive psychology. Applied Cognitive Psychology, 25(3), 432-442. doi:10.1002/acp.1710

Yordanov, S. (2013). Vlianie na zanimaniata s boino-prilojni tehniki za spraviane s depresivnite sastoiania pri choveka [Influence of training of compat-applied techniques for coping with human depression]. Sport \& Science, 57(Special issue), 307-311. 